\title{
'Parts of Speech' - 'Drop a Card' Board Game
}

\section{Angeline Ranjethamoney Vijayarajoo', Kuldip Kaur Maktiar Singh²,} Gan Kiat Chien ${ }^{3}$, Roslina Mohd Jani ${ }^{4}$

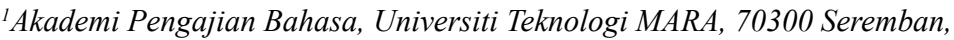
Negeri Sembilan

2,3,4 Akademi Pengajian Bahasa, Universiti Teknologi MARA, 78000 Alor Gajah, Melaka

\section{E-mail:}

angierv@uitm.edu.my,kksekhon@melaka.uitm.edu.my,gan_kiat@melaka.uitm.edu.my, aremjay143@yahoo.co.uk

Received: 23 January 2019

Accepted: 6 May 2019

Online First: 26 June 2019

\section{ABSTRACT}

Learning grammar can be difficult for learners but this can be changed through interactive activities. Language games are an excellent way to make learning grammar fun among learners. Although the use of language games is not a new tool in the teaching and learning of grammar, employing the right game for a specific grammar item is vital. Hence, this study aims to experiment, using a language game - 'Parts of Speech' - 'Drop a Card' board game, in efforts to enhance the learning of the parts of speech more effectively. This game is designed to provide practice in identifying the parts of speech in the English language. By playing this game, it is believed that learners will be able to engage and learn grammar in a funfilled way. Methodology comprised quantitative and qualitative methods, using questionnaire and interview, with the participants, who were college students. The results of the survey demonstrate the effectiveness of the game in the identification and learning of parts of speech. The pedagogical implications are that suitable language games can enhance grammar competence.

Keywords: parts of speech, grammar games, board game 


\section{INTRODUCTION}

Due to the changes in the perspectives of English language teaching and learning on communicative approach in the last few years, grammar has been pushed to the background. The structural view in the early $20^{\text {th }}$ century focused on linguistic competency. However, learners were unable to communicate in the language (Kolln \& Hancock, 2005), hence giving rise to the communicative approach. The consequences of this, with regards to grammar teaching and learning is grammar is not important, it is boring and grammar rules are difficult to understand. Hence it is essential for teachers to have interesting activities to motivate students. For this reason, one such means is language games which can be a refreshing and engaging to introduce grammar into the classroom. The researchers of this study felt that students' knowledge of the parts of speech was particularly lacking. This inspired the researchers to design the 'Parts of Speech' (POS) - 'Drop a Card Board Game', in order to engage and provide the fun element for students to be able to identify and understand the parts of speech.

\section{PROBLEM STATEMENT}

Due to the changing curriculum backdrop of the education system with emphasis on different aspects, grammar got left behind and many students in school lack grammatical knowledge. Furthermore, grammar learning is always perceived as a boring lesson when taught using the textbook, chalk and talk methods. Hence, the traditional teaching and learning methods are not successful in motivating learners to engage actively in grammar learning (Matas \& Natolo, 2010). In addition, Maros, Tan and Khazriyati (2007) found that learners from six rural schools had difficulties using correct English grammar in their writings. Furthermore, a study by Nor Hashimah et al (2008), showed that the most obvious weaknesses of the students' language ability lay in grammar. A study by Saadiyah and Kaladevi (2009), indicated that students generally have problems applying correct grammatical rules in their writings. Games have been found to make grammar lessons more interesting, enjoyable, motivating and effective (Metom et al., 2016). This study proposes a board game where the focus is to help students to identify and recognise the parts of speech in a more engaging, motivating and competitive spirit. It is hoped that this would be a 
step towards bringing grammar back into the classroom in a more engaging and fun way, through a board game.

\section{LITERATURE REVIEW}

Games are a useful strategy to promote students' language proficiency (Richard-Amato, 1996). Hadfield (1990) defined games as 'an activity with rules, a goal and an element of fun'. The 'Parts of Speech' - 'Drop a Card' Board Game has a set of rules, the goal of which is to be able to identify the parts of speech as required of them, according to what is stated on the tile of the board. The fun element is to get the correct part of speech card to match the tile and to quickly move to the finish line. Language games is an excellent way to make learning grammar fun among learners (Metom et al., 2013; Eskandari et al., 2014). Games also introduce an element of competition into language-building activities which provides valuable impetus to a purposeful use of language (Prasad, 2003).

An action research conducted by Huyen and Nga (2003) showed that the students liked the relaxed atmosphere and the researcher reported that the students seemed to learn more quickly and retain the learned materials in a stress-free and comfortable environment. When learners are placed in a game-based context, instead of focusing on the correctness of linguistic forms, learning shift their attention to winning the game, this eases the anxiety of negative evaluation and helps to generate the speech fluency (Chen, 2005). Among some of the benefits of using games in language learning, are the fact that these games are learner-centred, increase learning motivation, reduce learning anxiety, integrate various linguistic skills (parts of speech, in the current study), construct a cooperative learning environment and foster participatory attitudes of the students.

Hence, it has been established that traditional teaching and learning methods are not successful in motivating learners to engage actively in grammar learning (Matas \& Natolo, 2010). Games have been recommended to make the grammar lesson more interesting, enjoyable, motivating and effective (Metom, et al., 2016). Based on previous studies as shown in the literature, it can be concluded that learning grammar can be fun if there are interesting activities to motivate students. 


\section{METHODOLOGY}

This research uses quantitative and qualitative methods. The quantitative part comprised a questionnaire, which was analysed via SPSS tools while the qualitative part comprised interviews. Hence, the research instruments used were the questionnaire survey and the interview. The questionnaire is found in Appendix 1 and the interview questions are found in Appendix 2.

The respondents were diploma students in semester one, taking English during the Interim session, in a local public university. Their English language proficiency grades were based on their SPM results as the students were a fresh intake taken in directly after the SPM (Sijil Pelajaran Malaysia) or Form 5 examination. All the students had achieved Grade A in their English language at the SPM level. The questionnaire consisted of three parts: Section A, B and C. Section A consisted of the respondents' demographic information (gender, age and faculty). Section B consisted of ten items relating to the respondents' perceptions on grammar (parts of speech), while Section C consisted of ten items on the respondents' perceptions on the Parts of Speech Board Game. The analysis reports and discusses Sections $\mathrm{B}$ and $\mathrm{C}$ of the questionnaire.

Before playing the board game, brief instructions were given to the players on how to play the game. The rules of the game were also printed on the box for them to refer to. After playing the game, all the respondents were given the questionnaire to fill. Participants' responses were measured on a 5-point Likert scale ranging from 1 (strongly disagree) to 5 (strongly agree). After responding to the questionnaire, the respondents were interviewed individually.

\section{RESULTS AND DISCUSSION}

\section{Findings of the Questionnaire}

The questionnaire data formed the quantitative part of the research methodology. A total of 79 students participated in this questionnaire. Sections B and C are reported and discussed. For Part B, the researchers 
will mainly report the data on the students' perceptions of grammar. This data is found in Figure 1.

Question 10 was on the preference of learning grammar through games and this was significant with a mean of 4.33 . This showed that games were welcome in the classroom. The means on the participants' perceptions of their ability to identify the parts of speech are ranked in order of the highest means, though all were significant:

- Identification of verbs, showed significance of the mean, at 4.08,

- Identification of nouns, significance of the mean at 4.0,

- Identification of adjectives showed significance of the mean at 3.94,

- Identification of conjunctions showed significance of the mean at 3.86.

- Identification of pronouns, showed significance of the mean, at 3.73,

- Identification of adverbs showed significance of the mean at 3.67,

- Identification of prepositions showed significance of the mean at 3.54.

This shows that the participants were more confident with identifying verbs, nouns, adjectives, conjunctions, pronouns, adverbs and prepositions in that order. As for Question 1, the mean of 2.68, the lowest mean recorded but significant, was that the participants felt that learning grammar was difficult. Though significant, it was not as significant as the other items. Hence, it could be interpreted that the participants may have felt that they should not find difficulties in learning grammar. 


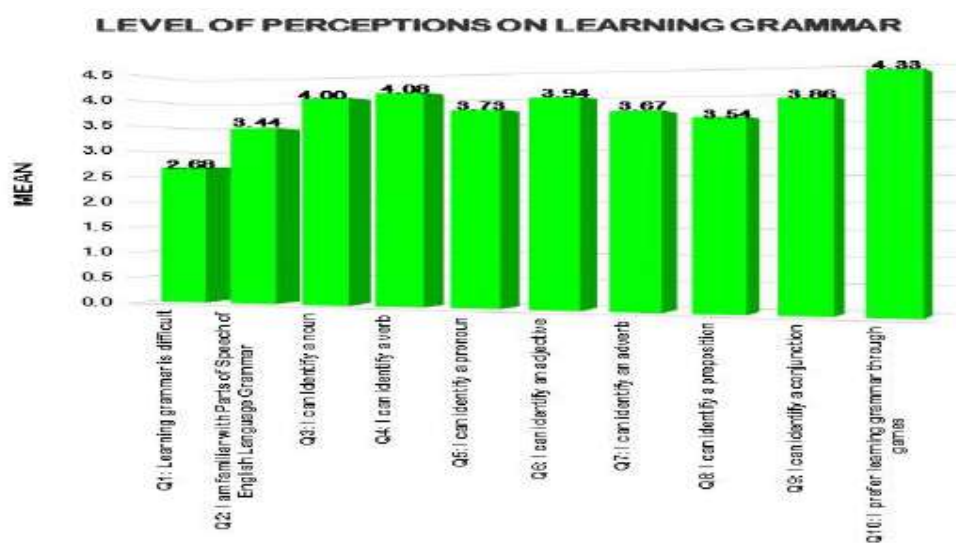

Figure 1: Mean Level of Perception on Learning Grammar

Part $\mathrm{C}$ as mentioned earlier focused on the board game. With reference to Figure 2 as shown below, for Question 1, the highest mean of 4.46, was significant in that the participants found playing the Parts of Speech Board Game fun and enjoyable. For Question 5, the mean of 4.44 was significant in that the participants found the rules of the game clear and easy to follow. This possibly contributed to their enjoyment of the game. Question 9 showed a mean of 4.43 , which was significant in that the participants felt that the POS game motivated them to learn grammar. This contradicted with Part B, where Questions 3 to 9 showed the participants' perceptions on the identification of parts of speech to be positively rated. If this were so, the participants would not have needed the game to be a learning tool for them. It appears that Part B responses were possibly what the participants felt to be the 'correct' response to state, shying away from their lack of knowledge on grammar.

In Question 4, the mean of 4.43 was significant in that the participants found playing the game to have helped them to understand the parts of speech better, again, in contradiction with part B of the questionnaire as noted above, while showing their better understanding of the parts of speech, through the game. The next highest mean of 4.34 was significant in that the POS game improved communication between the participants. Hence, communication featured highly in the game where interaction amongst the participants was valued. 
In Question 7, the mean of 4.27 was significant in that the participants stated that the answer key provided was helpful. The participants constantly referred to the answer key as they needed to confirm, clarify and counter check answers. This only confirmed that the participants' knowledge on the parts of speech was limited and they needed external help, in the form of the answer key. In Question 2, the mean of 4.00 was significant in that the participants found the POS game challenging. The game could be challenging due to the lack of knowledge and the search for the right cards and ultimately, the right answers.

In Question 6, the mean of 3.76 was significant in that the participants stated that the POS board game was time consuming. This could be either because they were unable to identify the parts of speech cards or didn't have in their hands, the correct cards required and had to keep on picking cards from the pack until they got the right card.

In Question 3, the mean of 3.68, was still significant, but not as significant as the above questions, in that the participants found the POS game easy to understand. The rules were straight forward and how the game was to be played appeared to be easily understood by the participants. 


\section{LEVEL OF PERCEPTIONS ON "POS" BOARD GAMES}

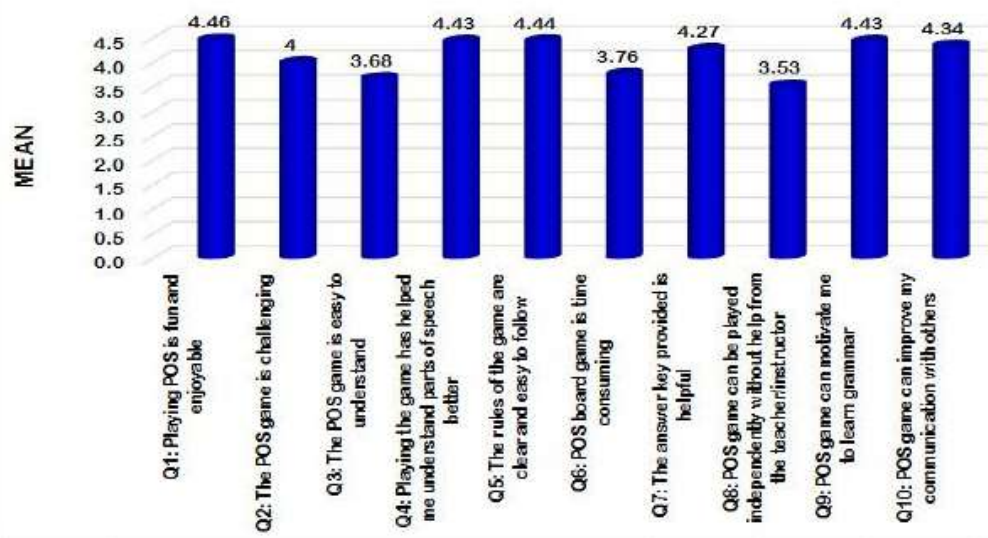

Figure 2: Mean Level of Perceptions on POS Board Game

\section{Findings of the Interview}

The interview data formed the qualitative part of this study's research methodology. 30 students were interviewed and the interview questions are found in Figure 2 . The reasons why only 30 students were chosen for the interview were firstly, time constraints. Secondly, the interview data was used to triangulate the questionnaire data. Hence, it was felt that 30 would be sufficient, considering the study was conducted in a small scale involving only a small group of students. The interview was conducted after the students had played the POS game. The interview data were reported and interpreted as well as compared against the questionnaire data.

For Question 1, all 30 respondents stated that they enjoyed the game. The reasons for their enjoyment are seen in the subsequent questions. For Question 2, majority of the respondents elaborated and stated that the most interesting part of the POS game included the ways in which the game enhanced their ability to think, increase their knowledge of grammar and their ability to identify the parts of speech. Apart from that, some responded that what made the game interesting was getting the correct card to match the part of speech required and also winning the game. This healthy competitive nature is present where games are concerned, as opposed to traditional 
ways of teaching. Hence, by playing games, a by-product is the learning made easier. Three students said that an interesting part of the game was the chance it afforded them in communicating with each other. This also shows that students like to talk to each other and not just listen to instruction, as passive recipients of knowledge from an authority. Discourse among peers is important where much learning takes place. Interaction among themselves was very much valued.

These comments were in line with Section C, Question 10 of the questionnaire where the mean was significant at 4.34 where the respondents agreed that the POS board game had helped them to improve their communication skills.

A cross reference to Question 1 of Section C, of the questionnaire, showed that majority of the participants found playing the game to be fun and enjoyable. This was echoed in the first and second interview responses. The interview enabled the participants to elaborate on their enjoyment and the reasons for their enjoyment, which are listed above.

Question 4 of Section $C$ of the questionnaire also showed the mean of 4.43, was significant in that the participants agreed that the game helped them to understand the parts of speech, thus concurring with the interview responses to question one.

Question 3 was about the most challenging part of the game, where the majority responded that getting the correct answer posed such a challenge. This trend was expressed in terms of getting the right card to match the part of speech required, if it was not at hand. The picking up of cards from the central pile was challenging and frustrating during the instances where the respondents could not get the card they required. Having to pick up cards challenged them as it meant falling further away from the Finish tile, as one could not move along the board without getting the right card to match what is stated on the tile on the board. Yet, to some, it was challenging enough that they were unable to identify the part of speech required of them when their tokens landed on the tiles of the board. This confirms the research gap, that knowledge of and identification of the parts of speech are not well understood by students in the Malaysian context. 
A cross reference to the second question in Section B of the questionnaire showed that the results were in conflict with the interview responses where the participants responded positively towards being familiar with the various parts of speech. This was not reflected in the interview responses nor in the observations of the researchers while the participants were playing the game. Questions 2-9 of Section B of the questionnaire showed a relatively high score of the respondents' perceptions of their ability to identify the specific parts of speech. This did not tally with the interview responses, where almost all the participants said that it was a difficult game to play due to the lack of knowledge. Once again, the reason for this data can only be inferred that these inaccuracies could be due to their own beliefs of what they 'should' know at this stage. Hence, they could have responded positively, in Section B of the questionnaire. Some of the participants may have shied away from being honest, on their lack of knowledge on the parts of speech. Some could have misunderstood the Likert Scale against the statements in the questionnaire. Furthermore, the second question in Section $C$ of the questionnaire, showed a significant mean at 4.00 , where the participants stated that the game was challenging. The interview questions allowed for the expansion of these 'challenges'. Hence, this data confirms that section B data for Questions 2-9 in the questionnaire, is erroneous.

Question 4 of the interview showed that majority of the respondents preferred learning grammar through games due to the following reasons: Games kept them alert, it was fun, interesting, enabled them to gain much, allowed them to play which they loved and hence, provided a platform for play while facilitating ways of learning for the visual learners. Games also helped them to remember better while 'socialising with friends'. Words and phrases used by the students included 'not sleepy', 'not so boring', 'more fun', 'more interesting lah', 'gain much', 'can learn more', 'a visual learner', 'help me remember better', 'interact with each other...helps our communication skills too'.

A cross reference to Question 10 of Part B in the questionnaire showed a mean of 4.33 , which was significant in showing that the respondents preferred learning grammar through games. This data, tallied with the interview responses where the participants said that they preferred playing the game over traditional textbooks as they loved to play, socialise and be actively involved in the learning process, as opposed to being in a traditional 
classroom context, as passive listeners to the teacher/ authority. It seems that only Question 10 of Section B was accurately answered by the participants. This opened up possibilities for the researchers to improve the questionnaire in considering other factors, including explaining the Likert scale, before the questionnaire is filled out by the participants.

Responses to Question 5 of the interview confirmed the research gap again, as majority of the students responded that the problems they faced playing the game was that they could not identify the parts of speech, which was the crux of the game. 14 students said that this was a problem while nine said that it was not a problem. Out of the nine students who did not state this aspect as a problem, one stated that friends had helped with the answers while another said that there were no problems, "just not sure of the parts of speech'. The other seven did not elaborate. One of the participants said that she did not have the cards at hand to put down, as stated on the tile of the board while the other said that 'maybe the cards are not shuffled perfectly, that I don't have the cards to drop'. These responses could be a camouflage of a lack of knowledge or a technical problem of the game. When further queried, it was found that the participants were not sure of the parts of speech.

Some of the participants' responses included 'I couldn't identify which part of speech it is', 'when I didn't know how to identify the adverb', 'confusing', 'because I don't know which is noun, verb or something...', 'I am confused with the preposition and conjunction and adverbs', 'have problem in understanding the words [parts of speech]'. Others did not give a definite yes or no response, but sat on the fence, yet expressing their difficulties with the parts of speech. One of the participants said, 'a bit problem, the parts of speech that I can't understand'. She refused to give a definite yes or no to the question, which asked if there were problems encountered with the game.

A cross reference to the questionnaire showed that the responses on the perceptions on learning grammar were not accurately represented by the participants in Section B of the questionnaire. Some possibilities attributed for these inaccuracies have already been mentioned.

For Question 6, majority of the participants (21) said that they referred 
to the answer key. The answer key did not just provide the listings of words and the categories of the parts of speech that they belonged to, but also provided a definition of the various parts of speech followed by sentences identifying the position of and how the parts of speech are used. Hence, it can be said that majority of the students did not have the knowledge required to play the game. This was the cause of the frequent reference to the answer key. Two of the participants mentioned that they did not refer to the answer key as one of the lecturers was there to help them.

Question 7 of the interview was on whether the participants (players) got any help from their friends or lecturers. 23 of the participants said that they did receive help, mostly from their friends, who were also participants of the game as well as the friends who were watching them play the game. Two students said that they did not get any help while one said that she did get help 'sometimes'.

Question 8, received a unanimous response- that all the participants found the rules of the game easy. Only one participant replied, 'not too easy and not too difficult'. The researchers can draw the conclusion that the rules of the game that they had devised were easily comprehensible by the participants.

Question 9 was on whether the participants preferred learning grammar through games or textbooks. 27 of the participants chose games. Some of the reasons listed from the participants' responses were: 'easy to remember and understand', 'much more fun and less stress', 'because I am kinaesthetic', 'don't like reading', and 'fun and easy to get knowledge'. Two students said that they preferred textbooks over games for the simple reason that they feared enjoying the game too much that they may not focus on the learning part. Their words, 'I can identify my mistake better, when I play through game, I am more enjoyed, I may not focus, I may not focus, I may not get enough information for my knowledge' and 'because I afraid I too enjoy the game that I can't learn'. One of the participants said 'prefer both ways'. Hence, games were a preferred way of learning.

The last question, Question 10 was on whether the participants thought that the present POS game and other such games would benefit them or not. All 30 participants responded with a 'yes' and their reasons 
were encapsulated by the words and phrases such as these: 'fun, increased learning, don't like to read, textbooks hard to understand, boring textbooks, boring teacher, the class is sleepy with textbooks, everybody like to play games, if teacher beside me, I will be pressured...' These responses show that the students were very happy with the game, and the fact that they learned either incidentally of purposefully, through the medium of play and enjoyment.

\section{CONCLUSION}

From the above analysis and discussion of the data, it can be said that students lack grammatical knowledge and one way of bringing grammar back into the classroom is by using games, where they would be more engaged and find the learning process more enjoyable. What this study showed and confirmed from other studies was that the ambience of the classroom and the spaces which provide for opportunities to learn via interaction between peers and the instructor, in less formal circumstances favour greater learning. This may not always be possible but infusing the classroom methodology with such games would facilitate learning in safer and less stressful circumstances, especially grammar. Learners anxiety of negative evaluation would be reduced and enable them to generate new and refreshing learning strategies to cope with grammar. Most games are played in pairs or small groups (Jacobs \& Liu, 1996), as these small groupings provide opportunities for learners to learn from and apply what they have learnt, with each other. This experimental study confirms that games such as the POS board game, increase learners' understanding in grammar knowledge, in this case, the parts of speech.

Further research should push this game to a greater dimension of how the parts of speech feature in sentences and perhaps even move into the digital sphere of learning. The limitation in the present study was not teaching the parts of speech as a revision or re-visiting the grammar components prior to the study. This is because there may be students who may be familiar with the parts of speech but yet need revision to recall what they have learnt. Hence, future research should consider incorporating revision prior to conducting a study or perhaps undertake an experimental study by comparing pre-test and post-test results to determine the effectiveness of the 
board game. These areas should be explored and more research conducted where the understanding of the parts of speech could go into the written and oral usage platforms.

\section{REFERENCES}

Chen, I. J. (2005). Using games to promote communicative skills in language learning. The Internet TESL Journal, 11(2). Retrieved from http://iteslj. org/Techniques/Chen-Games.html

Eskandari Z., Khonmohammad H. \& Komeijanifarahani A. A. (2014). The effect of using games on English grammar with focus on Iranian young learners of English. International Journal of Language Learning and Applied Linguistics World, 5(1), 458-471.

Huyen, N. T. T. \& Nga, K. T. T. (2003). The effectiveness of learning vocabulary through games. Asean EFL Journal, 5(4). Retrieved from http://asian-efl-journal.com/dec_03_vn.pdf

Hadfield, J. (1990). Intermediate Communication Games: A Collection of Games and Activities for Low to Mid-Intermediate Students of English. Hong Kong: Thomas Nelson and Sons Ltd.

Jacobs, G. M. \& Liu, K. K. (1996). Integrating language functions and collaborative skills in the second language classroom. TESL Reporter, 29, 21-33.

Kolln, M. \& Hancock, C. (2005). The story of English grammar in United States schools. English Teaching: Practice and Critique, 4(3), 1131. Retrieved from https://education.waikato.ac.nz/research/files/ etpc/2005v4n3art1.pdf

Maros, M., Tan, K. H. \& Khazriyati, S. (2007). Interference in learning English: Grammatical errors in English essay writing among rural Malay secondary school students in Malaysia. E-BANGI: Jurnal Sains Sosial dan Kemanusiaan, 2(2), 15. 
Matas, C.P. \& Natolo, M. (2010) Love Grammar: Student-driven Grammar Learning Games. The International Journal of Learning, 17(10), 371382. DOI: $10.18848 / 1447$ 9494/CGP/v17i10/47309

Metom, L., Tom, A. A. \& Joe, S. (2013). Mind your grammar! Learning English grammar the fun way. Journal of Educational \& Social Research, Special Issue, 3(7), 402-407. DOI: 10.5901/jesr.2013. $\mathrm{v} 3 \mathrm{n} 7 \mathrm{p} 402$

Metom, L., Tom, A. A., Joe, S. \& Awang Rozaimie Awang Shuib (2016) The grammar odyssey. European Journal of Language and Literature Studies, 2(3). http://dx.doi.org/10.26417/ejls.v6i1.p54-63

Nor Hashimah, J., Norsimah M. A. \& Kesumawati, A. B. (2008). The mastery of English language among lower secondary school students in Malaysia: A linguistic analysis. European Journal of Social Sciences, 7(2), 106-119.

Prasad, U. (2003, July 29). Achieving communicative competence in English. The Hindu. Retrieved from http:/www.thehindu.com/thehindu/ edu/2003/07/29/stories/2003072900010200.htm

Richard-Amato, P. A. (1996). Making It Happen: Interaction in the Second Language Classroom. New York: Addison-Wesley Publishing Group.

Saadiyah, D. \& Kaladevi, S. (2009). Error analysis of the written English essays of secondary school students in Malaysia: A case study. European Journal of Social Sciences, 8(3), 483-495. 